\title{
Prevalence of Parafunctional Habits among Preschool Children and its Correlation to Parental Education Status
}

\author{
Huda R. Mahdi Alawsi*, Bayan A. Hassan, Shaho Z. Jamil Al-Talabani \\ Department of Pedodontics Orthodontics and Preventive Dentistry, College of Dentistry, Hawler Medical University, Erbil, Kurdistan Region, \\ Iraq
}

\section{*Corresponding author: Huda R. Mahdi Alawsi, Department of Pedodontics Orthodontics and Preventive Dentistry, College of Dentistry, Hawler Medical University, Erbil, Kurdistan Region, Iraq. E-mail: rameematrooshi@ gmail.com}

Received: 10 September 2020 Accepted: 17 January 2021 Published: 30 June 2021

\section{DOI}

10.25156/pti.v11n1y2021.pp42-45

\section{A B S T R A C T}

Background: Parafunctional habit has been associated in the literature with alterations of dental occlusion; it could be a predisposing factor for malocclusion. This cross-sectional study is aimed to assess the prevalence of parafunctional habits and its relation to parent's education. Subjects and Methods: Convenience sample of 500 children aged between 4 and 6 years of both gender 262 boys and 238 girls receiving their medical care in primary health-care centers and in Raparin Pediatric Hospital of Erbil city to study parafunctional habits and its relation to parents education. Results: Mouth breathing and nail biting were more prevalent habits in the included children than lip sucking and bruxism. The former habits prevalence showed no significant differences in children whose their parents education background are different (high, middle, or low education). Conclusion: Mouth breathing and nail biting were highly prevalent habits among preschool children in Erbil city. No significant association was found between the prevalence of bad oral habits and parents education.

Keywords: Parafunctional habits; Parents education; Preschool children

\section{INTRODUCTION}

A habit is a repetitive action that is being done automatically (Shahraki et al., 2012). (Yetmitan et al., 2010) stated that: An instinct physiological act of fetus while fed through placenta and at birth is called sucking, it is of two types: Nutritive and non-nutritive sucking. Nutritive sucking that provides the fetus with nutrients and non-nutritive sucking is practiced unconsciously to provide comfort. Non-nutritive sucking habits that include: Thumb $\backslash$ finger sucking, lip sucking and lip biting, mouth breathing, and tongue thrusting can contribute to malocclusion through exerting abnormal pressure on teeth and perioral structure that finally results in malocclusion (Phulari, 2011). Adenoids and obstruction in the nasal cavity may lead to mouth breathing habit, in which the mouth is used for breathing instead of the nose (Mosby's, 2009; Farid and Metwalli, 2010). Nail biting habits or what called onychophagia is a common untreated habit in children starts at 3-4 years old and its peak in 10 years of age and increases in adolescence, malocclusion of anterior teeth, root resorption and intestinal parasites are common complications of these habits (Tanaka et al, 2008). Bruxism is involuntary, unconscious, and excessive grinding of teeth, there are two main types of bruxism. Bruxism which occurs when people are awake can be called wakeful bruxism and at sleep can be called nocturnal bruxism. The main cause for bruxism has not been determined but is held to involve multiple factors (Lerardo et al., 2019; Polmann et al., 2019; Balanta-Melo et al., 2019). Tooth mobility, tooth pain, tooth wear, and temporomandibular joint problem are common squeal of bruxism (Paesani, 2010). As type of adjustment to problems, child may practice certain habits or express emotions in appropriate way become a defense mechanism against hostile environment (Gederi et al., 2013). A state of child well-being and satisfaction can be crucially influenced by environment a child grows in (Canut, 2005). The study carried out according to the prospective studies worldwide, which showed that children with parafunctional habits may suffer from underlying psychological or pathological problem, further the consequent possible adverse effects of those habits on psychological and occlusion development. The aim was to determine the prevalence of the parafunctional habits among preschool children in Erbil city and figuring out their possible association with parents education. 
The child nutrition and the sucking habit were found to be related to the level of education in parents (Farsi and Salama, 1997).

\section{SUBJECTS AND METHODS}

Convenience sample of 500 children aged between 4 and 6 years of both genders 262 boys and 238 girls receiving their medical care except dental care in primary health-care centers and in Raparin Pediatric Hospital in Erbil city.

\section{Inclusion Criteria}

Healthy children and born out of normal full-term delivery were included in the study.

\section{Exclusion Criteria}

Medically compromised children such as children with obstructive or anatomical originating mouth breathing habit, but not habitual to stay and sleep with mouth open not related to medical conditions (Bishara, 2001; Gill and Naini, 2011), presence of cleft lip and palate or any teeth anomalies such as tooth malformation, missing, or unerupted teeth. A structured questionnaire was answered by children's parents or guardians regarding their demographics and information about child age, gender, general health, presence or absence of parafunctional habits, and parents years of education which was classified as the following (Borges et al., 2010): high level (university), middle (high school), low (elementary), and uneducated (illiterate) and student.

Data analyses were performed using Statistical Package for Social Sciences (SPSS version 24). Chi-square test of association was used to compare proportions. " $P$ " $\leq 0.05$ was considered significant.

\section{RESULTS}

From total of 500 children were examined in the study, the boys were $52.4 \%$, and the girls children were $47.6 \%$. The mean age $\pm \mathrm{SD}$ of children was $50.54 \pm 8.70$ months. Mouth breathing, nail biting had the highest prevalence among parafunctional habits $(24.4 \%$ and $11.2 \%)$, respectively, while bruxism and lip biting prevalence were (0.4-0.0\%), respectively. In comparison, between boys and girls, boys demonstrated higher prevalence in mouth breathing habit while girls showed higher prevalence in nail biting habit (13.2-6.4\%), respectively. These details are shown in Table 1.

The prevalence of different habits in children according to different levels of mother education is shown in Table 2. It was noticeable that prevalence of both mouth breathing, nail biting, and bruxism was higher in children whose
Table 1: Prevalence of parafunctional habits

\begin{tabular}{lcccc}
\hline Oral Habit & Presence & \multicolumn{2}{c}{ Gender (\%) } & \multirow{2}{*}{ P-value } \\
\cline { 2 - 4 } of habit & Female & Male & \\
\hline \multirow{4}{*}{ Lip biting } & No & 47.4 & 52.2 & 0.9 \\
& Yes & 0.2 & 0.2 & \\
& Total & 47.6 & 52.4 & \\
& No & 47.6 & 52.4 & $\begin{array}{c}\text { No statistic are } \\
\text { Nail biting }\end{array}$ \\
& Total & 47.6 & 52.4 & $\begin{array}{c}\text { computed because } \\
\text { lip biting is a } \\
\end{array}$ \\
& & & & constant \\
Mouth breathing & No & 41.2 & 47.6 & 0.1 \\
& Yes & 6.4 & 4.8 & \\
& Total & 47.6 & 52.4 & \\
& No & 36.4 & 39.2 & 0.6 \\
& Yes & 11.2 & 13.2 & \\
& Total & 47.6 & 52.4 & \\
\hline
\end{tabular}

their mothers are housewives $(16.6 \%, 7.2 \%$, and $0.2 \%$, respectively.

Table 3 showed the prevalence of different habits in children according to different levels of father education. It was noticeable that the prevalence of both mouth breathing, nail biting, and bruxism was higher in children whose their fathers are low educated $(12.4 \%, 5 \%$, and $0.2 \%)$, respectively.

In Table 4, Pearson Chi-square test showed non-significant association between different habits and parents level of education.

\section{DISCUSSION}

This cross-sectional study was conducted to assess the prevalence of oral parafunctional habits among preschool children in Erbil city. Mouth breathing was highly prevalent among the study samples $(24.4 \%)$, followed by nail-biting habit $(11.2 \%)$, bruxism $(0.4 \%)$, and lip biting $(0 \%)$.

In the context of prevention and early treatment of disorder, parafunctional habits and malocclusion are an important issue, cause these deleterious habits can interfere with physiological balance of skeletal growth pattern and tooth position. For instance, air way obstruction can result in mouth breathing and as a result exerts abnormal force in the oral musculature that consequently results into malocclusion. Many studies found that mouth breathing was closely related to increased overjet, reduced overjet, anterior or posterior cross-bite, open-bite, and displacement of contact points, one of these studies was done by Grippaudo et al., 2016.

In this study, mouth breathing was more prevalent habit $(24.4 \%)$ which may indicate the importance of seeking early treatment for the affected children to prevent malocclusion, 
Table 2: Mother educational level versus habits

\begin{tabular}{|c|c|c|c|c|c|c|c|c|c|c|c|}
\hline \multirow{2}{*}{$\begin{array}{l}\text { Mother } \\
\text { education } \\
\text { level }\end{array}$} & \multicolumn{3}{|c|}{ Mouth_breathing (\%) } & \multicolumn{3}{|c|}{ Nail_biting (\%) } & \multicolumn{2}{|c|}{ Lip_biting (\%) } & \multicolumn{3}{|c|}{ Bruxism (\%) } \\
\hline & No & Yes & Total & No & Yes & Total & No & Total & No & Yes & Total \\
\hline High level & $45(9)$ & $9(1.8)$ & $54(10.8)$ & $49(9.8)$ & $5(1.0)$ & $54(10.8)$ & $54(10.8)$ & $54(10.8)$ & $54(10.8)$ & $0(0)$ & $\begin{array}{c}54 \\
(10.8)\end{array}$ \\
\hline $\begin{array}{l}\text { Middle } \\
\text { level }\end{array}$ & $78(15.6)$ & $29(5.8)$ & $107(21.4)$ & $93(18.6)$ & $14(2.8)$ & $107(21.4)$ & $107(21.4)$ & $107(21.4)$ & $106(21.20$ & $1(0.2)$ & $\begin{array}{c}107 \\
(21.40\end{array}$ \\
\hline Low level & $4(0.8)$ & $0(0)$ & $4(0.8)$ & $3(0.6)$ & $1(0.2)$ & $4(0.8)$ & $4(0.8)$ & $4(0.8)$ & $4(0.8)$ & $0(0)$ & $4(0.8)$ \\
\hline $\begin{array}{l}\text { House } \\
\text { wife }\end{array}$ & $246(49.2)$ & $83(16.6)$ & $329(65.8)$ & $293(58.6)$ & $36(7.2)$ & $329(65.8)$ & $329(65.8)$ & $329(65.8)$ & $328(65.6)$ & $1(0.2)$ & $\begin{array}{c}329 \\
(65.8)\end{array}$ \\
\hline Student & $5(1)$ & $1(0.2)$ & $6(1.2)$ & $6(1.2)$ & $0(0)$ & $6(1.2)$ & $6(1.2)$ & $6(1.2)$ & $6(1.2)$ & $0(0)$ & $6(1.2)$ \\
\hline Total & $378(75.6)$ & $122(24.4)$ & $500(100.0)$ & $444(88.8)$ & $56(11.2)$ & $500(100.0)$ & $500(100.0)$ & $500(100.0)$ & $498(99.6)$ & $2(0.4)$ & $\begin{array}{c}500 \\
(100.0)\end{array}$ \\
\hline
\end{tabular}

Table 3: Father_eduactional level versus habits

\begin{tabular}{|c|c|c|c|c|c|c|c|c|c|c|c|}
\hline \multirow{2}{*}{$\begin{array}{l}\text { Father } \\
\text { education } \\
\text { level }\end{array}$} & \multicolumn{3}{|c|}{ Mouth_breathing (\%) } & \multicolumn{3}{|c|}{ Nail_bitimg (\%) } & \multicolumn{2}{|c|}{ Lip_biting (\%) } & \multicolumn{3}{|c|}{ Bruxism (\%) } \\
\hline & No & Yes & Total & No & Yes & Total & No & Total & No & Yes & Total \\
\hline High level & $55(11)$ & $13(2.60$ & $68(13.6)$ & $61(12.2)$ & $7(1.4)$ & $68(13.6)$ & $68(13.6)$ & $68(13.6)$ & $68(13.6)$ & $0(0)$ & 68 (13.6) \\
\hline Middle level & $116(23.2)$ & $44(8.8)$ & $160(32)$ & $137(27.4)$ & $23(4.6)$ & $160(32)$ & $160(32)$ & $160(32)$ & 159 (31.8) & $1(0.2)$ & $160(32)$ \\
\hline Low level & $199(39.8)$ & $62(12.4)$ & $261(52.2)$ & 236 (47.2) & $25(5)$ & 261 (52.2) & 261 (52.2) & $261(52.2)$ & $260(52)$ & $1(0.2)$ & $261(52.2)$ \\
\hline Uneducated & $7(1.4)$ & $3(6)$ & $10(2)$ & $9(1.8)$ & $1(0.2)$ & $10(2)$ & $10(2)$ & $10(2)$ & $10(2)$ & $0(0)$ & $10(2)$ \\
\hline Student & $1(0.2)$ & $0(0)$ & $1(0.2)$ & $1(0.2)$ & $0(0)$ & $1(0.2)$ & $1(0.2)$ & $1(0.2)$ & $3(0.6)$ & 0 & $3(0.6)$ \\
\hline Total & $378(75.6)$ & $122(24.4)$ & $500(100)$ & $444(88.8)$ & $56(11.2)$ & $500(100)$ & $500(100)$ & $500(100)$ & 498 (99.6) & $2(0.4)$ & 500 (100) \\
\hline
\end{tabular}

Table 4: Pearson Chi-square values of parents education and different oral habits

\begin{tabular}{|c|c|c|c|c|c|c|}
\hline \multirow[t]{2}{*}{ Oral habits } & \multicolumn{3}{|c|}{ Father education } & \multicolumn{3}{|c|}{ Mother education } \\
\hline & $\begin{array}{l}\text { Pearson } \\
\text { Chi-square }\end{array}$ & d.f & $P$-value & $\begin{array}{l}\text { Pearson } \\
\text { Chi-square }\end{array}$ & d.f & $P$-value \\
\hline $\begin{array}{l}\text { Mouth } \\
\text { breathing }\end{array}$ & $4.414 \mathrm{a}$ & 4 & 0.661 & $4.890 \mathrm{a}$ & 4 & 0.280 \\
\hline Nail biting & $2.508 a$ & 4 & 0.541 & $1.871 a$ & 4 & 0.753 \\
\hline Bruxism & $0.522 a$ & 4 & 1 & $1.088 a$ & 4 & 0.564 \\
\hline
\end{tabular}

in the same direction, (Aloumi et al., 2018) in Riyadh, found that mouth breathing was the second more prevalent habit $(13.8 \%)$ in 435 preschool children aged 3-6 years old which support the results of the present study.

The habitual mouth breathing is strongly related with different malocclusion such as anterior open bite, overjet, distal occlusion, underdeveloped and narrow upper jaw, and increased anterior facial height (Valcheva et al., 2017). Such results emphasize early diagnosis and cessation of such bad habit to normalize occlusion.

Malocclusion of the anterior teeth and apical root resorption is frequent consequence of non-physiological forces acting on the teeth due to nail biting habit (Oshio, 2018). Many studies worldwide had found that nail-biting is very prevalent habits among preschool children, for instance, (Soares-Silva et al., 2019) in brazil, found that $53.8 \%$ of children had nail biting habits, and in the present study the prevalence of nail biting was $11.2 \%$ in preschool children. Aloumi et al., 2018, concluded that nail-biting habit was highly prevalent habit among preschool children in Riyadh, which support the results of the present study and emphasizing the need for pediatric dentists to promote parents and caregivers about the risks of mouth breathing and nail biting since it can result in malocclusion. Refer of children to professionals for multidisciplinary assistance is advisable to minimize these risks and prevent dentofacial problem.

(Dhull et al., 2018 in India, found that lip-biting was most prevalent oral habit $(13.4 \%)$ in children. In contrast to the findings of the present study in which lip biting prevalence was $0 \%$. Jaw clenching and bracing with tooth contact that is known asbruxism, is multifactorial; it can be caused by stress conditions, occlusal disorders, and/or allergies (Murali and Rangarajan, 2015).

Out of 500 preschool children, bruxism was the least prevalence habits $(0.4 \%)$, this result is in agreement with Aloumi et al., 2018 study, who found that bruxism was least prevalence of habit $(6 \%)$.

Essential factors include maternal education, knowledge, attitude, and behavior which can be a contributing factors in improving mothers and children health attitude indirectly (Wigen and Wang, 2012). Previous study performed by Omer and Abuaffan, 2015, showed that significant difference was observed between mother education (university level) and oral habits $(P=0.018)$. In the present study, the prevalence of parafunctional habits was higher 
in children whose their mothers are housewives, this might be because, housewives are not motivated enough about the consequence of bad oral habits, so they cannot help children discourage those habits. Chi-square test showed non-significant relation between mother education and prevalence of bad habits in children $(P=0.280, P=0.753$ and 0.564$)$, respectively, for mouth breathing, nail biting, and bruxism habits.

In the present study, children of middle and low educated fathers showed higher prevalence of oral habits such as mouth breathing, nail biting, and bruxism, although Chisquare test showed no significant association between father education and prevalence of oral habits in children (0.661, 0.541 , and 1 , respectively). This is might be due to sample size.

\section{CONCLUSION}

Among parafunctional habits, mouth breathing, and nail-biting had higher frequency in the studied groups. No significant differences were found between parent's education and prevalence of oral habits.

\section{REFERENCES}

Aloumi, A., A. Alqahtani and A. Darwish. 2018. Oral parafunctional habits among preschool children in Riyadh, Saudi Arabia. S. J. Oral Sci. 5(1): 22-27.

Balanta-Melo, J., V. Toro-lbacache, K, Kupczik and S. Buvinic. 2019. Mandibular bone loss after masticatory muscles intervention with botulinum toxin: An approach from basic research to clinical findings. Toxins (Basel). 11(2): 84.

Bishara, S., editor. 2001. Textbook of Orthodontics. W B Saunders Co., Philadelphia, PA. p606-17.

Borges, H. C., C. A. S. Garbín, O. Saliba, N. A. Saliba and S. A. S. Moimaz. 2012. Socio-behavioral factors influence prevalence and severity of dental caries in children with primary dentition. Braz. Oral Res. 26(6): 564-570.

Canut, J. 2005. Ortodonciaclínica y Terapéutica. $2^{\text {nd }}$ ed. MASSON, Barcelona.

Dhull, K. S., T. Verma and B. Dutta. 2018. Prevalence of deleterious oral habits among 3- to 5-year-old preschool children in Bhubaneswar, Odisha, India. Int. J. Clin. Pediatr. Dent. 11(3): 210-213.

Farid, M. and N. Metwalli. 2010. Computed tomographic evaluation of mouth breathers among paediatric patients. Dentomaxillofac.
Radiol. 39(1): 1-10.

Farsi, N. and F. Salama. 1997. Sucking habits in Saudi children: Prevalence, contributing factors and effects on the primary dentition. Pediatr. Dent. 19(1): 28-33.

Gederi, A., K. Coomaraswamy and P. Turner. 2013. Pacifiers: A review of risks vs benefits. Dent. Update. 40(2): 92-101.

Gill, D. and F. Naini. 2011. Orthodontics: Principles and Practice. $1^{\text {st }}$ ed. Wiley Blackwell, Hoboken, New Jersey. p281.

Grippaudo, C., E. Paolantonio, G. Antonini, R. Saulle, G. La Torre and R. Deli. 2016. Association between oral habits, mouth breathing and malocclusion. Acta Otorhinolaryngol. Ital. 36(5): 386-394.

Lerardo, G., M. Mazur, V. Luzzi, F. Calcagnile, L. Ottolenghi and A. Polimeni. 2019. Treatments of sleep bruxism in children: A systematic review and meta-analysis. Cranio. 26(1): 1-7.

MOSBY. 2009. Mosby's Medical Dictionary. $8^{\text {th }}$ ed. Elsevier, Amsterdam, Netherlands.

Murali, R. and P. Rangarajan. 2015. Bruxism: conceptual discussion and review. J. Pharm. Bioallied Sci. 7(1): S26.

Omer, M. and A. Abuaffan. 2015. Prevalence of oral habits and its effect in primary dentition among Sudanese preschool children in Khartoum City. Indian J. Dent. Educ. 8(2): 57-62.

Oshio, A. 2018.Who shake their legs and bite their nails? Self-reported repetitive behaviors and big five personality traits. Psychol. Stud. 63(4): 384.

Paesani, D. 2010. Bruxism Theory and Practice. Quintessence Publishing Co., Chicago.

Phulari, B. 2011. Orthodontics Pricioles and Practices. $1^{\text {st }}$ ed. Jaypee Brothers Medical Puplisher, India.

Polmann, H., F. Domingos, G. Melo, J. Stuginski-Barbosa, E. N. Guerra, A. Porporatti, B. Dick, C. Flores-Mir and G. De Luca Canto. 2019. Association between sleep bruxism and anxiety symptoms in adults: A systematic review. J. Oral Rehabil. 46(5): 482-491.

Shahraki, N., S. Yassaei and M. Moghadam. 2012. Abnormal oral habits: A review. J. Dent. Oral Hyg. 4(2): 12-15.

Soares-Silva, L., C. Tavares-Silva, A. Fonseca-Gonçalves and L. C. Maia. 2019. Presence of oral habits and their association with the trait of anxiety in pediatric patients with possible sleep bruxism. J. Indian Soc. Pedod. Prev. Dent. 37(3): 245-250.

Tanaka, O., R. F. Vitral, G. Tanaka, A. Guerrero and E. Camargo. 2008. Nailbiting, or onychophagia: A special habit. Am. J. Orthod. Dentofac. Orthop. 134(2): 305-308.

Valcheva, Z., H. Rnautska, M. Dimova, G. Ivanova and I. Atanasova. 2018. The role of mouth breathing on dentition development and formation. J. IMAB. 24(1): 1878-1882.

Wigen, T. and N. Wang. 2012. Parental influences on dental caries development in preschool children. An overview with emphasis on recent Norwegian research. Norsk Epidemiol. 22(1): 13-19.

Yetmitan, T., O. da Costa, O. Sanue and M. C. Isiekwe. 2010.The effects of digit sucking on dental arch dimensionsin primary dentition. Afr. J. Med. Med. Sci. 39(1): 55-61. 